\title{
The influence of curing temperature, plastic additives and polypropylene fibers on the mechanical behaviour of cementitious materials.
}

\author{
Mohammed Aqil ${ }^{1,}{ }^{*}$, Lahcen Bahi ${ }^{1}$, Latifa Ouadif ${ }^{1}$, Siham Belhaj ${ }^{1}$ and Raounak Edderkaoui ${ }^{2}$ \\ 13GIE Laboratory, Mineral Engineering Department, Mohammadia Engineering School, Mohammed V University, Rabat, Morocco \\ ${ }^{2}$ LASH Laboratory, Civil Engineering Department, Mohammadia Engineering School, Mohammed V University, Rabat, Morocco
}

\begin{abstract}
An experimental company was carried out to better understand the influence of curing temperature on the mechanical behaviour of cementitious materials, particularly compressive strength, the study focused on two types of mortars, the first containing polypropylene fibers while the second contains a proportion of PVC-type plastic grains from industrial waste, the hydration kinetics of the different components of the formulated mortar has been characterized by the isothermal calorimetric test, thus a history of the hydration degrees has been established, Afterwards, an attempt was made to correlate the compressive strength with the evolution of the degree of hydration for the different formulations, based on the results obtained, it is clearly observable that the compressive strength evolves with the degree of hydration and that the specimen containing the polypropylene fibers has the best mechanical performance with respect to compression.
\end{abstract}

\section{Introduction}

The mechanical performance of structures based on cementitious materials is influenced by microstructural temperature and water behaviour[1], particularly the departure of water during drying[2], thus understanding the behaviour of cementitious materials with regard to the thermal effect remains relatively complex, recent research works has shown that a high temperature at the fresh state has a negative impact on the final compressive strength of concrete, but a rise in the cured state has a positive effect $[3,4,5,6,7]$.

The description of the thermal effect on the structural behaviour of concrete necessarily leads us to a thorough understanding of the hydration kinetics of cement and particularly the reaction that governs this phenomenon and which is obviously $\mathrm{C} 3 \mathrm{~A}+\mathrm{C} 3 \mathrm{~S} \rightarrow \mathrm{C}-\mathrm{S}-\mathrm{H}+$ ettringities $[8,9]$.

this reaction begins at the beginning of contact between cement and water, as $\mathrm{C} 3 \mathrm{~S}$ interacts with $\mathrm{C} 3 \mathrm{~A}$ and forms $\mathrm{C}-\mathrm{S}-\mathrm{H}$ and ettringites, previous studies have shown that this reaction is exothermic and thermoactivated [10,11], during concrete pouring, the heat released by this exothermic character causes thermodynamic effects whose damages are no longer negligible, especially when we talk about massive structures such as dams and road works or structures in aggressive environments such as port dams or reservoirs. the research work carried out so far on the thermal behaviour of cementitious materials $[12,13]$ has led to the fact that:

$\checkmark$ The degree of hydration is significantly independent of the curing temperature

$\checkmark \quad$ the increase in cure temperature causes a slight increase in absorbed sulphate and incorporated aluminium

$\checkmark$ the polymerization of $\mathrm{C}-\mathrm{S}-\mathrm{H}$ increases with temperature

the problem posed in this current research work is that we have other elements that are added in the reaction between cement and water, namely PVC-type plastic interposing through $(\mathrm{C} 2 \mathrm{H} 3 \mathrm{Cl}) \mathrm{n}$ and polypropylene fibres embodying through $(\mathrm{C} 3 \mathrm{H} 6) \mathrm{n}$ which have been used as substituents[14,15].

In this paper we will compare the evolution of hydration degree for different curing temperatures and for several mortars, among them those containing plastic additives and fibres and we will compare the results found with those of the reference mortar.

\begin{tabular}{|c|c|c|c|}
\hline $\begin{array}{c}\text { Round } \\
\text { section }(\mu)\end{array}$ & Diameter $(\mu \mathrm{m})$ & Length $(\mathrm{mm})$ & Eltivation(L/D) \\
\hline 15 & 32 & 12 & 375 \\
\hline
\end{tabular}




\section{Materials and methods}

\section{2-1 Materials}

Three types of mortars were carried out, the first is the reference mortar, the second contains a proportion of polypropylene fibers with different quantities $(10 \%, 20 \%, 30 \%, 40 \%)$, and the third includes a volume of plastic grains of type PVC coming from the industrial waste.

The cement used is the CPJ 55 seawater intake manufactured in Morocco and more precisely within the Lafarge-Holcim plant in Meknes, a specific surface Blaine of $359,6 \mathrm{~m} 2 / \mathrm{kg}$, an absolute density of 3080 $\mathrm{kg} / \mathrm{m} 3$ and an average compressive strength at 28 days of $48,47 \mathrm{MPa}$ is used for all mixtures of sand concrete.

as part of the recovery of local materials we have opted to use sand extracted from the Oued du Sebou in the Sefrou region type $0 / 4$, the formulations and the physico mechanical characteristics of the different constituents are described in the tables below:

Table 1. Mix design of the formulated mortars

\begin{tabular}{|c|c|c|c|c|c|c|}
\hline $\begin{array}{l}\text { Components } \\
\text { (Kg/m3) }\end{array}$ & Cement & Sand & LF & Water & $\begin{array}{c}\text { Plastic } \\
\text { grains }\end{array}$ & PP fibers \\
\hline Ref LF & 350 & 1627 & 235 & 292,5 & 0 & 0 \\
\hline LF+PPF (0.5\%) & 348.25 & 1627 & 235 & 291.0375 & 0 & 1.75 \\
\hline LF+PPF (1\%) & 346.5 & 1627 & 235 & 289.575 & 0 & 3.5 \\
\hline LF+PPF (1.5\%) & 344.75 & 1627 & 235 & 288.1125 & 0 & 5.25 \\
\hline LF+PPF (2\%) & 343 & 1627 & 235 & 286.65 & 0 & 7 \\
\hline LF+PG (10\%) & 350 & 1464.3 & 235 & 292.5 & 162.7 & 0 \\
\hline LF+PG (20\%) & 350 & 1301.6 & 235 & 292.5 & 325.4 & 0 \\
\hline LF+PG (30\%) & 350 & 1138.9 & 235 & 292.5 & 488.1 & 0 \\
\hline LF+PG (40\%) & 350 & 976.2 & 235 & 292.5 & 650.8 & 0 \\
\hline
\end{tabular}

Table 2. Cement properties

\begin{tabular}{|c|c|c|c|c|c|c|}
\hline \multicolumn{7}{|c|}{ Constituants } \\
\hline \multicolumn{3}{|c|}{ With gypse } & \multicolumn{3}{c|}{ Without gypse } \\
\hline Clinker & Calcaireous & Pzz & Gypsum & Clinker & Calcaireous & Pouzz \\
\hline 75,60 & 20,90 & & 3,50 & 78,34 & 21,66 & 0,00 \\
\hline
\end{tabular}

Table 3. LF, PVC grains and polypropylene fibers properties

PVC:

\begin{tabular}{|c|c|c|c|c|}
\hline Diameter(mm) & Density(g/cm3) & Harshness & $\begin{array}{c}\text { Tensile strength } \\
\text { (MPA) }\end{array}$ & $\begin{array}{c}\text { Elongation } \\
\text { at break (\%) }\end{array}$ \\
\hline 0,33 & 0,96 & 55 & 55 & 190 \\
\hline
\end{tabular}

LF:

\begin{tabular}{|c|c|c|c|c|}
\hline $\begin{array}{c}\text { Granular } \\
\text { class }(\mathrm{mm})\end{array}$ & $\begin{array}{c}\text { Superficial } \\
\text { gloss }(\mathrm{m} 2 / \mathrm{Kg})\end{array}$ & $\begin{array}{c}\text { Water demand } \\
(\%)\end{array}$ & $\begin{array}{c}\text { Blue } \\
\text { value }(\mathrm{g} / \mathrm{kg})\end{array}$ & $\begin{array}{c}\text { Water } \\
\text { content (\%) }\end{array}$ \\
\hline $0-0,063$ & 555 & 0,6 & 0,66 & 0,13 \\
\hline
\end{tabular}

\begin{tabular}{|c|c|c|}
\hline $\begin{array}{c}\text { Specific } \\
\text { weight }(\mathrm{g} / \mathrm{cm})\end{array}$ & $\begin{array}{c}\text { Tensile } \\
\text { strength }(\mathrm{N} / \mathrm{mm} 2)\end{array}$ & $\begin{array}{c}\text { Elasticity coefficient } \\
(\mathrm{KN} / \mathrm{mm} 2)\end{array}$ \\
\hline 0,91 & $\mathbf{3 2 0}$ at $\mathbf{4 0 0}$ & 3,6 \\
\hline
\end{tabular}

\section{2-2 Testing methods}

for a better understanding of the phenomenon studied, we have opted to formulate small slabs Fig 1 of dimensions $150 * 15 * 7 \mathrm{~cm} 3$ :

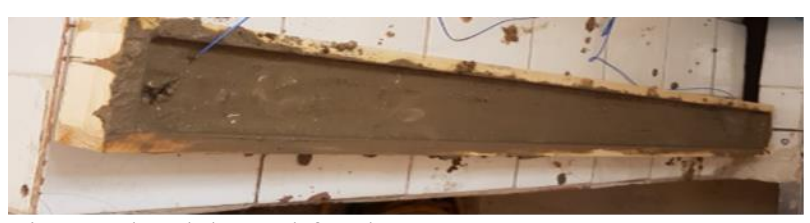

Fig 1 : The slab used for the test's measurements

The degree of hydration was measured for each of the four formulations and at different curing temperatures using the following equation:

$$
\zeta(t)=\frac{T_{a d}(t)-T_{0}}{T_{a d}(\infty)-T_{0}}=\frac{Q(T(t))}{Q\left(T_{\infty}\right)}
$$

The experimental devices employed are :

1-an isothermal calorimeter Fig 2 with a $700 \mathrm{ml}$ cylindrical aluminum container, an insulating chamber, a $700 \mathrm{ml}$ beaker $(100 \mathrm{~mm}$ diameter and $100 \mathrm{~mm}$ height), and a stirrer with a square cross-section rod.

Throughout the test, a servo system ensures the thermal insulation of the core of the enclosure by imposing a temperature around the core that cancels out the flow of heat output. This system consists of a series of thermocouples, arranged in series around the specimen, and a heating grid by Joule effect. The registration of the temperature is almost continuous ( 1 to 3 points per minute) from the beginning of the test.

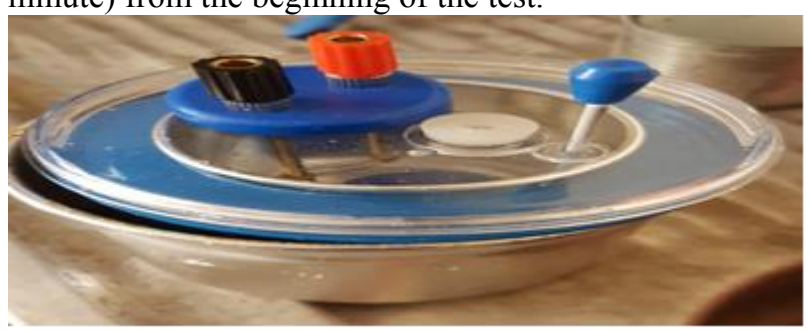

Fig 2 : Isothermal calorimeter

2- a thermocouple used for temperature measurement it is inexpensive and allow measurement over a wide range of temperatures which in our case reaches $70^{\circ} \mathrm{C}$. Their main defect is their accuracy: it is quite complex to obtain measurements with an error of less than $0.1{ }^{\circ} \mathrm{C}-$ $0.2{ }^{\circ} \mathrm{C}$. Temperature measurement by thermocouples is based on the Seebeck effect.

PP fibers: 


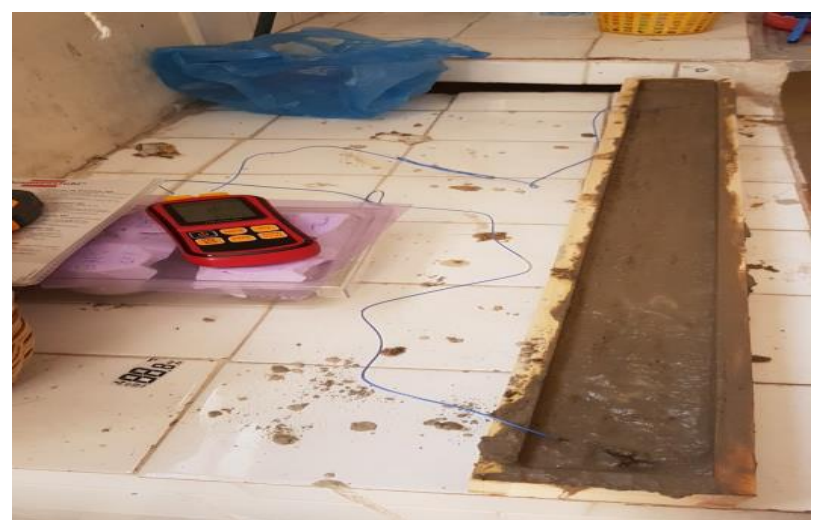

Fig 3 : the thermocouple used inserted into the small slab formulated

\section{Results and discussion}

\section{3-1-The degree of hydration evolution}

the results of the hydration degree history will be obtained from the coupling of the experimental measurements of the heat released via the isothermal calorimeter test and the heat release rate of a hydrating cement paste.

\section{REF LF Mortar}

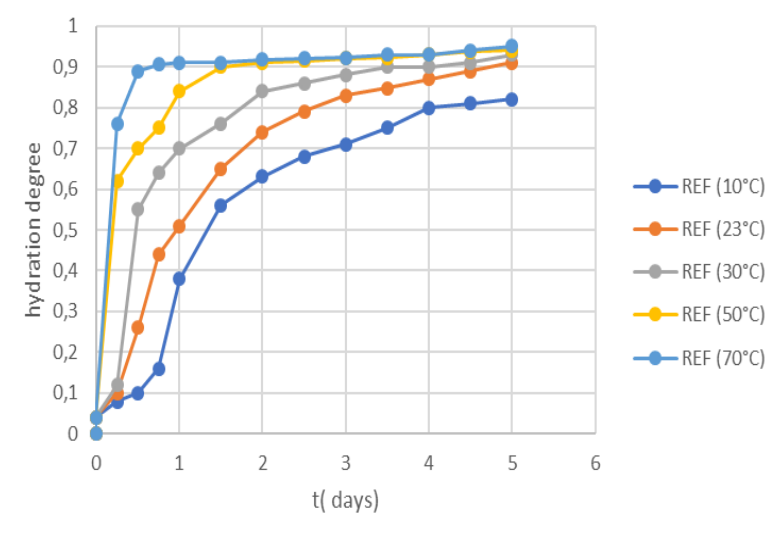

Fig 4: the experimental evolution of the degree of hydration for the reference mortar for different curing temperatures

in order to avoid repetition, we will present the results of the hydration history for a single mortar containing $1.5 \%$ of polypropylene fibres and another containing $20 \%$ of plastic grains in order to make a simple comparison with the reference mortar.

\section{LF $+\mathbf{1 . 5} \%$ PPF Mortar}

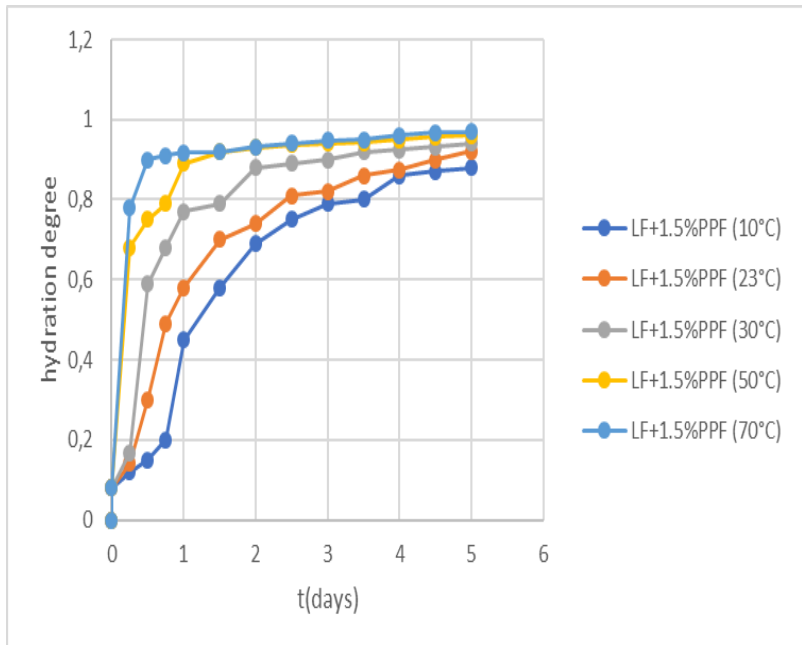

Fig 5 : the experimental evolution of the degree of hydration for the mortar containing $1.5 \%$ of polypropylene fibers for different curing temperatures

\section{LF $+20 \%$ GP Mortar}

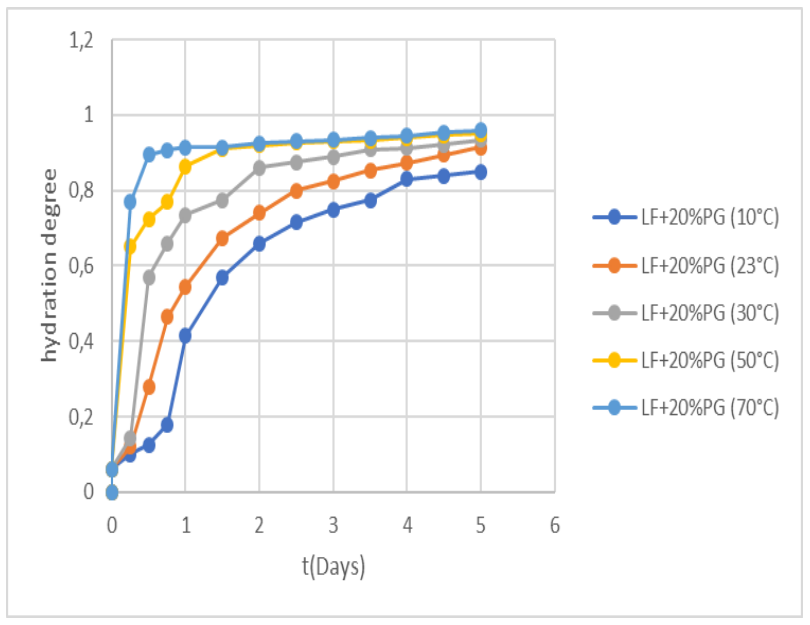

Fig 6 : the experimental evolution of the degree of hydration for the mortar containing $20 \%$ of plastic grains for different curing temperatures

\section{3-2-The compressive strength}

in this section we will present the evolution of compressive strength as a function of the degree of hydration for the different temperatures mentioned above and for the 3 mortars (reference, 1.5\%PPF, 20\%PG)

\section{REF LF Mortar}




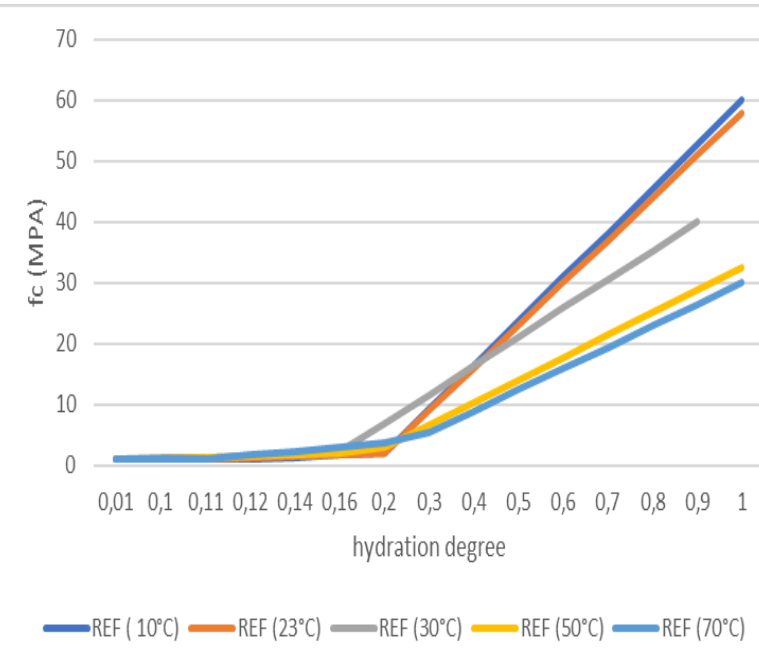

Fig 7 : the experimental evolution of the compressive strength as a function of the hydration degree for different curing temperatures for the reference mortar

\section{LF $+1.5 \%$ PPF Mortar}

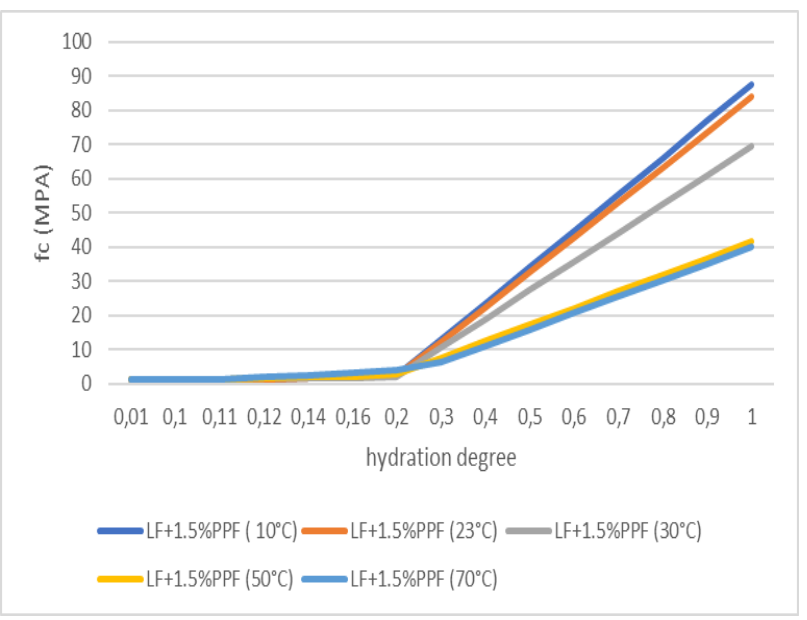

Fig 8 : the experimental evolution of the compressive strength as a function of the hydration degree for different curing temperatures for the mortar containing $1.5 \%$ of polypropylene fibers

\section{LF $+20 \%$ PG Mortar}

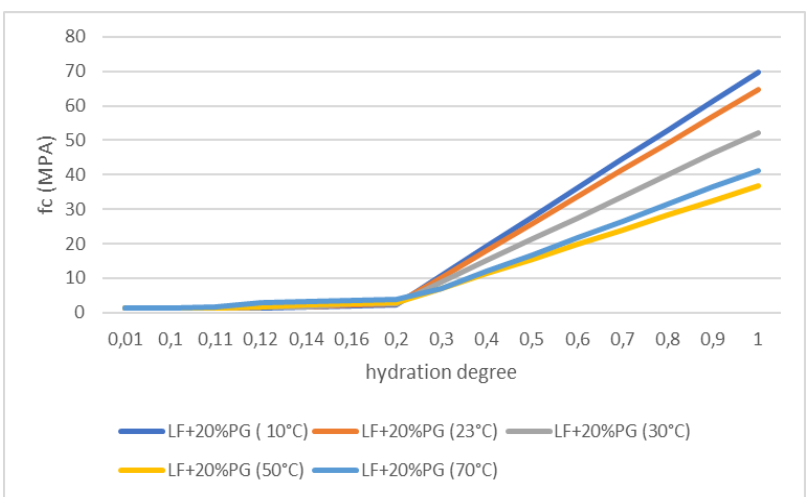

Fig 9 : the experimental evolution of the compressive strength as a function of the hydration degree for different curing temperatures for the mortar containing $20 \%$ of plastic grains

\section{3-3-Discussion of experimental results}

We note from the results of the experimental company that the behaviour of concrete regarding the thermal effect remains relatively complicated, in fact we note that the evolution of the degree of hydration registers a significant increase with the curing temperature for the different mortars formulated.

In addition, the degree of hydration increases but slightly with the addition of plastic additives and polypropylene fibres this is explained by the accelerating role that $(\mathrm{C} 2 \mathrm{H} 3 \mathrm{Cl}) \mathrm{n}$ and $(\mathrm{C} 3 \mathrm{H} 6) n$ play in the hydration reaction.

concerning the mechanical resistance to compression, this paper confirms the results found in the previous published articles, polypropylene fibres play a crucial role in improving the mechanical behaviour of cementitious meteors regarding compression.

However, we notice that the final compressive strength depends not only on the composition of the mixture but also on the cure temperature, in fact we notice that this strength decreases significantly with the increase in temperature regardless of the mortar formulation, this could probably be explained by the increase in porosity, which facilitates the penetration of water into the porous network.

For a temperature $\mathrm{T}>\sim 50{ }^{\circ} \mathrm{C}$ we notice a significant slowing down of the compressive strength for the different formulated mortars, this is explicated by the fact that the hydration reaction for tricalcium aluminate in ordinary Portland cement is altered, monosulfate phases become more and more stable as compared to ettringite, as monosulfate has a higher density, capillary porosity may increase at very higher curing temperatures and water can penetrate easily the porous body of the 
structure which generate an increasing $\mathrm{E} / \mathrm{C}$ rate and consequently a decreasing in compressive strength.

\section{4-prediction model of hydration reaction applied for the reference mortar at $23^{\circ} \mathrm{C}$}

We will try through this chapter to create a continuous model that describes the history of hydration levels for the reference mortar at the curing temperature $23^{\circ} \mathrm{C}$ based on some experimental data such as the heat released at 48 hours.

According to the law of Arrhenius we have:

$$
\frac{d \zeta}{d t}=A(\zeta) \exp \left(-\frac{E a}{R T}\right)
$$

Where $S$ is the degree of hydration, $\mathrm{A}$ is the thermal affinity, Ea is the activation energy, $\mathrm{T}$ is the temperature degree considered equal to $23^{\circ} \mathrm{C}$ in the modelling part and $\mathrm{R}$ is the international constant of perfect gases.

considering $\mathrm{Q}$ as the heat released and $\mathrm{Q}_{1}$ the heat released limit which is considered in our case equal to $442.5 \mathrm{~J} / \mathrm{g}$, we can obtain from (1) that:

$$
\zeta(t)=\frac{\int_{0}^{t} \frac{\pi}{Q(\tau)} d \tau}{Q l}
$$

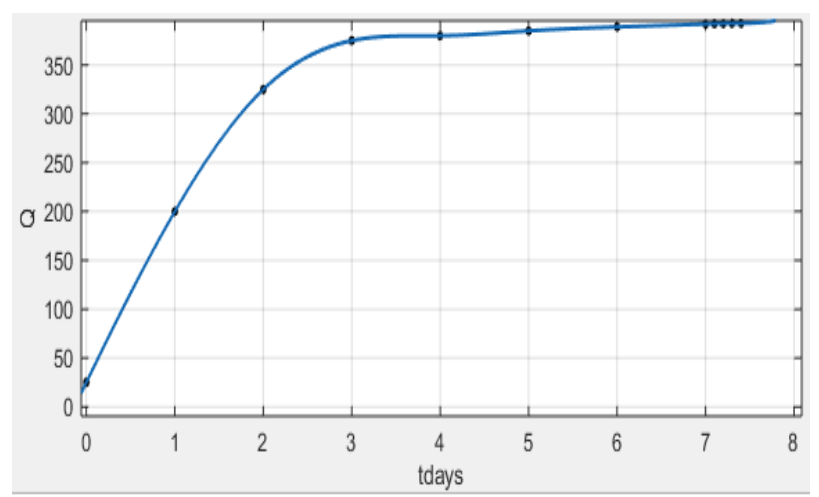

Fig 10 : the numerical evolution of the released heat as a function of time for the reference mortar at $23^{\circ} \mathrm{C}$.

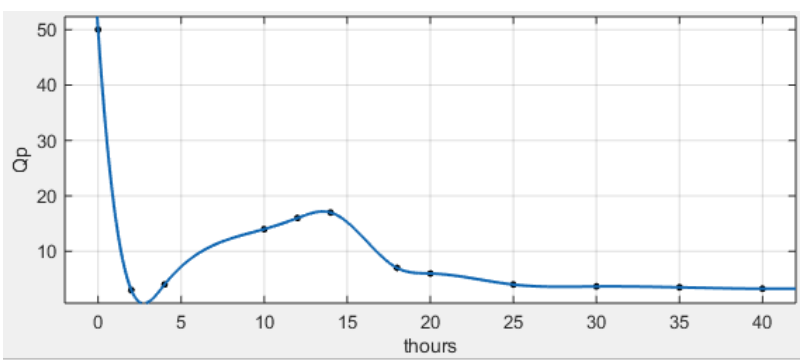

Fig 11 : the numerical evolution of the released heat rate as a function of time for the reference mortar at $23^{\circ} \mathrm{C}$.

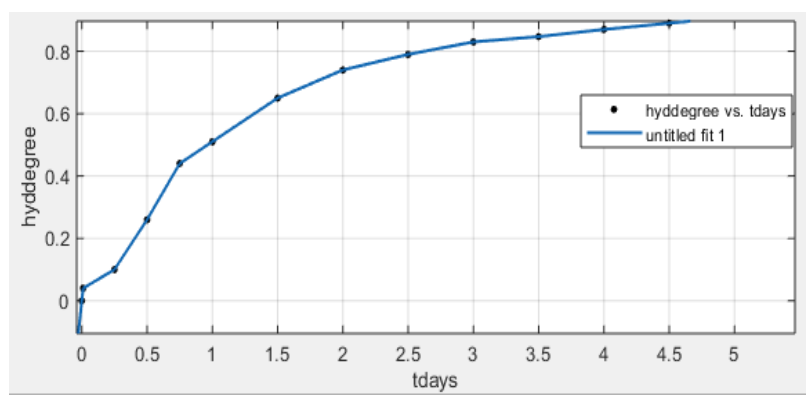

Fig 12 : the numerical evolution of the hydration degree as a function of time for the reference mortar at $23^{\circ} \mathrm{C}$.

\section{5-conclusion}

the conclusions drawn from this experimental company carried out on a small concrete slab in order to obtain reliable and realistic results have enabled us to have (1) a history of the mechanical compressive strength for different curing temperatures ranging from $10^{\circ} \mathrm{C}$ to $70^{\circ} \mathrm{C}$ and for different formulations as well, (2) the hydration kinetics of Portland cement used in the concrete mix design.

From what above it can be deduced once again that polypropylene fibers and plastic additives operate through their chemical composition respectively $(\mathrm{C} 3 \mathrm{H} 6) n$ and $(\mathrm{C} 2 \mathrm{H} 3 \mathrm{Cl}) n$ which interact with $\mathrm{C} 3 \mathrm{~S}$ and $\mathrm{C} 3 \mathrm{~A}$ and contribute by the way in accelerating the hydration reaction and therefore engender the increasing of hydration degree.

The proposed model with considering the effect of curing temperature reasonably estimate the compressive strength and degree of hydration of pastes cured at any conditions.

it is finally necessary to achieve the fact that only the formulation and curing temperature do not allow a global understanding of the mechanical behaviour of cementitious materials, there is still a fundamental parameter to be studied which is the internal relative humidity and which has a direct relation with the shrinkage phenomenon, fundamental source of curling and cracks.

\section{References}

[1] B. Pichler, C. Hellmich, J. Eberhardsteiner, J. Wasserbauer, P. Termkhajornkit, R. Barbarulo, G. Chanvillard, Effect of gel-space ratio and microstructure on strength of hydrating cementitious materials : an 
engineering micromechanics approach, Cem. Concr. Res. 45 (0) (2013) 55-68.

[2] H.M. Jennings, A. Kumar, G. Sant, Quantitative discrimination of the nano-porestructure of cement paste during drying: new insights from water sorption isotherms, Cem. Concr. Res. 76 (2015) 27-36

[3] M. Königsberger, B. Pichler, C. Hellmich, Micromechanics of ITZ-aggregate interaction in concrete, Part II: strength upscaling, J. Am. Ceram. Soc. 97 (2) (2014) 543-551

[4] B. Craeye, M. Geirnaert, G.D. Schutter, Super absorbing polymers as an internal curing agent for mitigation of early-age cracking of high-performance concrete bridge decks, Constr. Build. Mater. 25 (1) (2011) 1-13.

[5] S. Zhutovsky, K. Kolver, Effect of internal curing on durability-related properties of high-performance concrete, Cem. Concr. Res. 42 (1) (2012) 20-26

[6] Y.D. Han, J. Zhang, Y.M. Luosun, T.Y. Hao, Effect of internal curing on internal relative humidity and shrinkage of high strength concrete slabs, Constr. Build. Mater. 61 (2014) 41-49.

[7] M.-M. Zhou, G. Meschke, Strength homogenization of matrix-inclusion composites using the linear comparison composite approach, Int. J. Solids Struct. 51 (1) (2014) 259-273

[8] A.J. Allen, J.J. Thomas, H.M. Jennings, Composition and density of nanoscale calcium-silicate-hydrate, Nat. Mater. 6 (2007) 311-316.

[9] E. Gallucci, X. Zhang, K.L. Scrivener, Effect of temperature on the microstructure of calcium silicate hydrate (C-S-H), Cem. Concr. Res. 53 (2013) 185-195.

[10] P. Atkins, J. de Paula, Atkins' Physical Chemistry, 9th, Oxford University Press, New York, 2010

[11] LEE S. L., TAM C. T., SWADDIWUDHIPONG S. and MANI A. C. Temperature distribution and thermal stresses in thick concrete pours. In 3rd International Conference on Structural Failure, Singapore, 1991, pp. 17-33.

[12] BENTZ D. P., WALLER V. and LARRARD F. Prediction of adiabatic temperature rise in conventional and high-performance concretes using a 3-D microstructural model. Cement and Concrete Research, 1998, 28, No. 2, 285-297.

[13] T.C. Powers, Structure and physical properties of hardened Portland cement paste, J. Am. Ceram. Soc. 41 (1958) 1-6.

[14] M. Aqil, L Bahi, L. Ouadif, S. Amgaad, A. Bouajaj, The Impact of the Addition of Plastic Additives, Polypropylene Fibers and Specimen Shape on drying Shrinkage and Mass Loss of High-Performance Sand Concrete, International Journal of Civil Engineering and Technology (IJCIET) 9(13), 2018, pp. 1606-1614. http://www.iaeme.com/IJCIET/issues.asp?JType=IJCIE T\&VType=9\&IType $=13$

[15] M. Aqil, L. Bahi, L. Ouadif and S. Amgaad, Rochan Trivedi and Sidharth, Green Buildings: Review, International Journal of Civil Engineering and Technology, 9(6), 2018, pp. 1617-1632. http://www.iaeme.com/ijciet/issues.asp?JType=IJCIET\& VType $=9 \&$ IType $=6$ 